\title{
Inflammatory bowel disease and pregnancy: Evidence, uncertainty and patient decision-making
}

\author{
Flavio M Habal MD PhD FRCP, Varun Kapila MD MSc
}

FM Habal, V Kapila. Inflammatory bowel disease and pregnancy: Evidence, uncertainty and patient decision-making. Can J Gastroenterol 2009;23(1):49-53.

Inflammatory bowel disease (IBD) often affects women during their child-bearing years. Management of a pregnant IBD patient, or a patient contemplating pregnancy, poses unique challenges and can be quite daunting. Knowledge of the basic interplay among disease, normal host physiology and pregnancy is vital to managing these patients. One of the most important advances in the management of IBD over the past decade has been the finding that normal pregnancy outcomes can be achieved when a woman enters the pregnancy in remission. New insights into the safety of a wider spectrum of drugs in these patients has allowed for increased success in IBD management. The evidence supporting medical interventions including biological therapy such as antibodies to tumour necrosis factor agents is reviewed. Once the treating physician understands this complex relationship, management of the pregnant IBD patient can often become a rewarding experience.

Key Words: Biologics; Bowel; Inflammatory; Management; Pregnancy; Therapy

$\mathrm{T}$ he interaction between inflammatory bowel disease (IBD) and reproduction appears to be complex and the complete relationship has not yet been elucidated. Because ethical considerations generally preclude conducting randomized controlled trials in pregnant patients, the majority of the available information has been gathered from retrospective studies. Decisions regarding management of pregnant IBD patients thus requires a review of the current information and careful clinical judgement.

The age of onset of IBD peaks between 15 and 25 years. As a result, many questions to which definitive answers do not exist - and may never exist - may pose dilemmas for women in their childbearing years: whether to become pregnant and if so, when; whether to breastfeed; and whether to continue or change treatment during pregnancy. Effective patient counselling requires the clinician to be familiar with the available information on these topics.

Further complicating the management of the pregnant IBD patient is the development of newer therapeutic agents. Biological treatment strategies aimed at inhibiting immune responses have changed the management of chronic inflammatory conditions, including IBD. Many of the traditional drugs including 5-aminosalicylic acid (5-ASA)-based compounds, steroids and immunomodulatory therapies have well-documented risk profiles in pregnancy. Previously, the use of rescue agents such as antitumour necrosis factor (TNF)-alpha therapies (infliximab,

\section{Les maladies inflammatoires de l'intestin et la grossesse : Les données probantes, l'incertitude et la prise de décision des patientes}

Les maladies inflammatoires de l'intestin (MII) touchent souvent des femmes en âge de procréer. La prise en charge de la patiente atteinte d'une MII enceinte ou qui envisage une grossesse comporte des défis particuliers et peut même devenir un défi de taille. Il est essentiel de connaître les interactions fondamentales entre la maladie, la physiologie d'un hôte normal et la grossesse pour prendre en charge ces patientes. Le fait qu'il soit possible pour une femme de vivre une grossesse normale si elle devient enceinte pendant une rémission constitue l'une des avancées les plus importantes de la prise en charge des MI depuis dix ans. De nouvelles observations sur l'innocuité d'un plus vaste spectre de médicaments chez des patients permettent de mieux réussir la prise en charge des MII. Les auteurs analysent les données probantes étayant les interventions médicales, y compris les thérapies biologiques telles que des anticorps aux agents du facteur de nécrose tumorale. Lorsque le médecin traitant comprend ce lien complexe, la prise en charge de la patiente enceinte atteinte d'une MIl devient souvent une expérience enrichissante.

Department of Medicine, Division of Gastroenterology, University of Toronto, Toronto, Ontario

Correspondence: Dr Flavio Habal, University of Toronto, University Health Network, 200 Elizabeth Street, Toronto, Ontario M5G 2C4. Telephone 416-

340-5023, fax 416-595-5251, e-mail flavio.habal@uhn.ca

Received and accepted for publication October 27, 2008. 
that the risk is decreased in breastfed infants (3). Genetic predisposition appears to play a greater role in the development of Crohn's disease (CD) than ulcerative colitis (UC) (4).

In the general population, approximately $4 \%$ of babies born every year have congenital abnormalities, an outcome similar to what is seen in retrospective studies of women whose IBD is treated during their pregnancy. Studies that report prematurity and small-for-gestational-age infants did not document maternal smoking, alcohol consumption, disease status and medication use.

\section{EFFECT OF IBD ON FERTILITY, PREGNANCY AND FETAL OUTCOMES}

\section{IBD and fertility}

Infertility rates in women with inactive $\mathrm{CD}$ are similar to those of the general population ( $8 \%$ to $10 \%$ ) (4). Active disease decreases fertility, possibly as a result of inflammation or adhesions in the fallopian tubes or ovaries, and may cause painful intercourse. Women who have undergone ileal pouch-anal anastomosis are also less fertile for reasons that are unclear (5). The optimal time for conception is during remission, and a minimum three-month duration of remission is recommended before attempting conception (6).

\section{Patient counselling}

Many clinicians believe it is important to discuss with patients issues related to conception and pregnancy early on, either at diagnosis or when medication is initially prescribed. Patients attempting to become pregnant should be counselled to start folic acid supplementation before discontinuing birth control, given its importance in preventing neural tube defects. Consideration should also be given to referral to a high-risk pregnancy program or one such as Motherisk (www. motherisk.org).

\section{IBD and pregnancy outcomes}

Studies conducted before the availability of biological agents reported an increase in adverse perinatal outcomes in women with IBD. A 1998 review by Subhani et al (7) found that CD, especially active disease, is associated with decreased birth weights, preterm delivery and caesarian section. Bush et al (8) performed a case-control study comparing 116 pregnancies in patients with IBD with 56,398 controls, and found no differences in antepartum complications, including chronic hypertension, hyperemesis gravidarum, preterm labour or pre-eclampsia. Among patients with IBD, however, induction of labour ( $32 \%$ versus $24 \% ; \mathrm{P}=0.002)$, chorioamnionitis $(7 \%$ versus $3 \% ; \mathrm{P}=0.04)$, and caesarian section ( $32 \%$ versus $22 \%$; $\mathrm{P}=0.007$ ) were all more frequent. Neonatal complications, including low birth weight (LBW), very low birth weight, intrauterine growth restriction, Apgar scores and congenital anomalies, were similar in both groups. Subgroup analysis found a decreased risk of LBW associated with previous IBD surgery, quiescent disease, and CD compared with UC.

Control of disease activity before conception and during pregnancy is critical for optimal maternal and fetal health $(8,9)$. Dejaco et al $(10)$ performed a prospective study assessing risk factors for poor pregnancy outcome in 58 patients with IBD. The authors found that active disease during pregnancy represents a significant risk factor for unfavourable birth outcome. These results support the current treatment guidelines, which state that the maintenance of remission during pregnancy is essential (11). Pregnant women should be treated as aggressively as women who are not pregnant.

Mahadevan et al (12) performed a large cohort study that matched 461 pregnant IBD patients to 495 pregnant women without IBD. The study found no association between active disease during conception or the first trimester and spontaneous abortion, or between disease activity during pregnancy and adverse pregnancy, labour or neonatal outcome. The majority of patients had inactive disease throughout the pregnancy, which may explain the lack of adverse outcomes in this study.

Cornish et al (13) recently published a meta-analysis of studies on the influence of IBD on pregnancy. The analysis reviewed 12 studies that met the inclusion criteria and reported outcomes of interest. The studies included 1952 women with CD, 1113 with UC and 320,531 controls. For women with IBD, the analysis found a 1.87 -fold increase in premature births (less than 37 weeks; $\mathrm{P}<0.001)$; more than double the incidence of LBW (less than $2500 \mathrm{~g} ; \mathrm{P}<0.001$ ); a 1.5-fold increase in caesarian section $(\mathrm{P}<0.001)$; and a 2.37 -fold increase in congenital abnormalities $(\mathrm{P}<0.001)$. The analysis was unable to determine which women had a higher risk of adverse outcomes, but the authors concluded that pregnant women with IBD should be treated as a high-risk group. Limitations include the observational nature of the studies that make them vulnerable to bias; the low incidence of adverse outcomes that makes statistical precision difficult; and the fact that disease activity was not reported in relation to outcomes. In addition, increased risks of congenital abnormalities associated with 5-ASA, azathioprine and anti-TNF-alpha medications seen in a pooled analysis may be associated with the disease and not the medications. The authors also pointed out the need for a definitive study to determine optimal management and to support the development of new guidelines to assist patients and clinicians in decision-making.

\section{Endoscopy during pregnancy}

Indications for endoscopy during pregnancy include significant or continued gastrointestinal bleeding, dysphagia, severe or refractory nausea and vomiting or abdominal pain, and a strong suspicion of a colonic mass $(14,15)$. No evidence exists that would suggest endoscopy could affect the pregnancy. Obstetrical support should be available in the event of a pregnancy-related complication, and the presence of fetal heart sounds should be confirmed before administering sedation before and after the procedure.

\section{IBD MEDICATIONS AND PREGNANCY}

$\mathrm{CD}$ and UC appear to be distinct diseases, which are partially mediated by different aspects of immune system dysfunction. CD is thought to be related to the overexpression of $\mathrm{T}$ cell helper (Th) 1 cytokines, such as TNF-alpha, which stimulate cellmediated immunity and result in transmural inflammation of the gut (16). In contrast, UC is believed to result from a dysregulation of intestinal immunity involving the Th2 cytokine response. Increased expression of TNF-alpha, however, has been observed in patients with UC.

Medications used to treat IBD generally do not affect fertility. Azathioprine has been shown not to affect in vitro fertilization success rates (17-19). Sulfasalazine, however, causes a reversible, dose-related decrease in male fertility from decreased sperm count and motility (4). Methotrexate, which is widely distributed in the tissues, persists in the liver for up to 116 days. Because mutagenesis has been demonstrated with methotrexate 
TABLE 1

Inflammatory bowel disease medications: Summary of safety data during pregnancy

\begin{tabular}{|c|c|c|}
\hline Medication & FDA category & Safety during pregnancy \\
\hline \multirow[t]{2}{*}{ 5-Aminosalicylic acid } & $\mathrm{B}^{*}$ & All shown to be safe: Very high doses of 5-aminosalicylic acid should be used with caution \\
\hline & & Sulfasalazine: Folate supplements required; kernicterus a potential but rare concern \\
\hline \multirow[t]{2}{*}{ Antibiotics $^{\dagger}$} & $\mathrm{B}$ & Short-course metronidazole seems safe for Trichomonas species \\
\hline & & Ciprofloxacin seems safe; arthropathogenicity possible, but not seen in major studies \\
\hline \multirow[t]{3}{*}{ Corticosteroids } & No rating & Generally well tolerated and safe in pregnancy \\
\hline & & Topicals are safe until third trimester, unless miscarriage or preterm delivery a concern \\
\hline & & Budesonide teratogenic and embryocidal in rats and rabbits, but safe during pregnancy when inhaled \\
\hline $\begin{array}{l}\text { Azathioprine, } \\
\text { 6-mercaptopurine }\end{array}$ & $D^{\ddagger}$ & Seems safe during pregnancy \\
\hline \multirow[t]{2}{*}{ Methotrexate } & $X^{\S}$ & Teratogenic and embryotoxic in animals, with chromosomal damage and miscarriage \\
\hline & & Used as an abortifacient in tubal pregnancies; should be avoided \\
\hline \multirow[t]{2}{*}{ Immunosuppressives } & $C^{\pi}$ & $\begin{array}{l}\text { Cyclosporine seems safe during pregnancy; low birth weight and prematurity association, but high } \\
\text { survival; abstract showed successful pregnancies in four of five mothers with inflammatory bowel disease }\end{array}$ \\
\hline & & $\begin{array}{l}\text { Tacrolimus seems safe; compares favourably with other immunosupressives with regard to congenital } \\
\text { malformations, birth weight and neonatal problems }\end{array}$ \\
\hline Infliximab & B & $\begin{array}{l}\text { Seems safe in murine models; postmarketing safety database demonstrates outcomes consistent } \\
\text { with those in healthy women }\end{array}$ \\
\hline
\end{tabular}

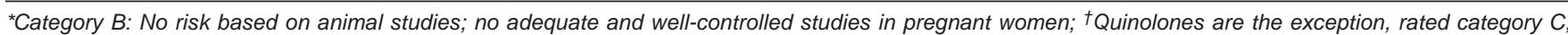
${ }^{\ddagger}$ Category D: Adverse reaction data provide evidence of human fetal risk; potential benefits may warrant use of the drug in pregnant women despite potential risks; $\S$ Category X: Human or animal studies demonstrate fetal abnormalities and/or adverse reaction data provide evidence of human fetal risk; risks in pregnant women clearly outweigh potential benefits; " Category C: Adverse fetal effects in animal studies; no adequate and well-controlled studies in pregnant women; potential benefits may warrant use of the drug in pregnant women despite potential risks; FDA United States Food and Drug Administration

use in cancer patients, this agent should be avoided in men (20). The literature suggests a four-month washout period $(21,22)$.

Many patients and family physicians mistakenly believe that pregnant patients with IBD should avoid medications (4). The majority of medications used to manage IBD, however, are considered safe to use during pregnancy (Table 1). Furthermore, the risks to the fetus of active disease substantially outweigh the risks of treating to control disease $(4,23,24)$.

A recent study by Moskovitz et al (23) assessed the effect of 5-ASA drugs, metronidazole, ciprofloxacin, prednisone, 6-mercaptopurine, azathioprine and cyclosporine on pregnancy outcomes in 113 IBD patients with 207 documented conceptions. The authors reviewed information on smoking history, birth weight, type of delivery and the following pregnancy outcomes: spontaneous abortion, therapeutic abortion, maternal or fetal illness resulting in abortion, premature birth, healthy full-term birth, multiple births, ectopic pregnancy and congenital defects. The study also analyzed the effect of medications on pregnancy outcomes during the first trimester and at any time during the pregnancy. No significant differences were seen among groups in outcomes, and a multivariate analysis controlling for maternal age showed no negative influence of any medication on pregnancy outcomes.

\section{5-ASA compounds and azathioprine}

At the 2006 Digestive Disease Week in Los Angeles, USA, Mahadevan and Corley (25) reported that the use of 5-ASA and sulfasalazine during pregnancy was not associated with an increase in adverse outcomes. A trend toward an increased risk of congenital malformations was seen during conception and the first trimester with sulfasalazine, but not with 5-ASA. On the contrary, an increased risk of adverse outcomes was seen in women not taking 5-ASA during the second and third trimesters, suggesting a protective effect of the medication. Because azathioprine is excreted in breast milk, breastfeeding is a contraindication to azathioprine use, although no harm to the infant has been demonstrated (26-28).

\section{Immunobiological therapy, pregnancy and lactation}

The role of TNF-alpha for embryonic implantation, fetal development and labour has been well studied. TNF-alpha controls arachadonic acid metabolism production through the cyclooxygenase pathway. Subsequently, TNF-alpha plays an important role in implantation and vascular permeability. TNF-alpha production is low in the first gestational trimester, but increases thereafter, reaching a peak at the onset of labour (29). These high levels have been shown to play an important role in the induction of the labour process and in delivery via augmenting uterine contractions. Most of the literature regarding anti-TNF-alpha therapy in pregnancy comes from studies in rheumatoid arthritis; however, reports in IBD patients are beginning to emerge.

Vasiliauskas et al (30) monitored a pregnant patient who continued on standard-dose infliximab therapy during her pregnancy and lactation. The measurement of serum infliximab in the breastfed infant was $39.5 \mu \mathrm{g} / \mathrm{mL}$ or less and the drug was not detected in the breast milk. Importantly, despite continued breast-feeding and adherence to therapy, the levels declined in the infant over the subsequent six months. They concluded that infliximab levels were likely due to placental transfer and less likely the result of breastfeeding (30). Importantly, the blood levels in the newborn were within the therapeutic range. The authors recommended that such therapy be avoided after 30 weeks gestation when possible (30). As of the date of this publication, no increased risk of embryotoxicity, teratogenicity or adverse pregnancy outcome has been reported in patients treated with anti-TNF therapy (31).

To date, there have been few comprehensive studies in IBD patients, many of which have been retrospective reviews. Roux 
et al (32) reported their experience with three rheumatoid arthritis patients who became pregnant while undergoing antiTNF-alpha therapy. Although one patient terminated her pregnancy despite no known pregnancy or fetal complications, the other two patients delivered healthy infants. Another study from the infliximab study database showed that 96 patients exposed to infliximab during pregnancy had outcomes no different than in the general population (33). In the first reported study of intentional infliximab administration for $\mathrm{CD}$ during pregnancy, Mahadevan et al (34) showed that all patients had excellent outcomes. All 10 pregnancies ended in live births and there were no congenital malformations, intrauterine growth retardation or small-for-gestational-age infants. Despite these promising results, three infants were born premature and one had LBW.

A review of the literature regarding breastfeeding during administration of anti-TNF therapy has not demonstrated any adverse outcomes. The data, however, appear limited. Recently, Stengel et al (35) published a case report in which serial sampling over a one-month time period failed to detect infliximab in breast milk. Furthermore, at a follow-up of just over two years, no developmental abnormalities were noted in the child. Ostensen et al (36) showed that etanercept, a soluble TNF-alpha receptor fusion protein, was detected in breast milk with maximal doses noted the day following the injection. The effect on the developing immune system in the infant - if indeed the levels in breast milk are significant - remains to be seen. The European Panel on the Appropriateness of Crohn's Disease Therapy (EPACT), an international multidisciplinary panel, met recently to develop safety criteria for clinical decision-making related to the use of drugs in pregnant and nursing women with IBD. The panel was cautious about the safety of infliximab, based primarily on label recommendations, and emphasized the need for further large, randomized controlled trials (37).

\section{EFFECT OF PREGNANCY AND THE POSTPARTUM PERIOD ON IBD}

\section{Pregnancy and IBD}

The effect of pregnancy on CD has not been well studied. Patients becoming pregnant while in remission have an approximately equal likelihood of staying in remission, improving or getting worse (38). Most observational studies have found that $\mathrm{CD}$ activity at conception correlates with $\mathrm{CD}$ activity during and after pregnancy. If conception occurs when the disease is inactive, the course of UC during pregnancy appears to be similar to that in the nonpregnant population (4). Approximately one-third of patients relapse during pregnancy, usually in the first trimester. If disease is active at the time of conception, however, activity is likely to persist or worsen in two-thirds of patients. As a result, patients should be strongly counselled to wait until the disease is in remission before trying to conceive.

Other studies have suggested that CD activity may be reduced during pregnancy, although most did not take smoking status into account. A retrospective analysis assessing the effect of pregnancy on CD activity in 61 women monitored the women regularly before, during and after pregnancy and took smoking behaviour into account (39). In women who smoked, the mean Harvey-Bradshaw Index (a clinical index used for CD) was significantly lower during pregnancy than in the years before or after pregnancy. No significant change was seen in the Index in nonsmoking women. The authors concluded that
$\mathrm{CD}$ activity was mildly reduced during pregnancy and that the reduction in tobacco consumption among smokers could have played a significant role in the improvement.

\section{Postpartum period and IBD}

IBD may flare during the postpartum period (40). Factors that may be involved include medication discontinuation, smoking resumption and postpartum hormonal changes. In vitro studies have shown that prolactin may possess proinflammatory properties.

Kane and Lemieux (40) investigated the association between breastfeeding and postpartum disease activity in 122 women with IBD, in relation to disease type and activity during and after pregnancy, medication use, smoking and breastfeeding. A significant proportion of women (56\%) did not breastfeed, citing fear of medication effects on the baby $(52 \%)$, physician recommendation $(30 \%)$ and personal choice $(18 \%)$ as the main reasons. Of women who did breastfeed, 74\% discontinued their IBD medication. An increased risk of postpartum disease activity was noted in patients who breastfed, but this effect disappeared when the analysis was adjusted for medication cessation. The authors concluded that the association seen between breastfeeding and postpartum disease flare may have been a consequence of medication discontinuation.

\section{SUMMARY AND CONCLUSIONS}

Women with IBD who are in remission at the time of conception appear to have a good chance of having a successful pregnancy with a normal fetal outcome $(38,39)$. With the exception of methotrexate, the majority of drugs appear to be effective and safe during pregnancy, including 5-ASA, antibiotics and corticosteroids. The safety of the newer biological agents on pregnancy has not been fully established. Infliximab is effective in certain patients with refractory disease, and pregnancy outcomes in more than 100 women taking infliximab did not differ from outcomes in the general population. The risks of increased $\mathrm{CD}$ activity during pregnancy appear to outweigh the risks of continued infliximab treatment in patients with severe disease. Anti-TNF therapy during pregnancy can be a safe adjunct to current medical management of these patients.

One of the most important advances in the management of IBD over the past decade has been recognizing that normal pregnancy outcomes can be achieved when a woman enters the pregnancy in remission. Maternal fears of taking medication that could potentially harm the fetus are understandable, but the potential harm should be weighed against the risks associated with discontinuing treatment $(4,23,24)$. Women with IBD should be informed of the increased risk of adverse pregnancy outcomes (13). Because the available evidence indicates that the best pregnancy outcomes are achieved during remission, women should be counselled to continue taking their medication to maintain remission. Additional studies are required to clarify IBD-realated issues and pregnancy to assist patient and clinician decision-making. However, the review of the literature to date suggests that a shift in thinking may be required - that current medical therapy, including anti-TNF agents, may indeed be a safe rescue treatment in pregnant patients.

\section{REFERENCES}

1. Orholm M, Binder V, Sørensen TI, Rasmussen LP, Kyvik KO.

Concordance of inflammatory bowel disease among Danish twins.

Results of a nationwide study. Scand J Gastroenterol 2000;35:1075-81.

2. Tysk C, Lindberg E, Järnerot G, Flodérus-Myrhed B. Ulcerative colitis and Crohn's disease in an unselected population of 
monozygotic and dizygotic twins. A study of heritability and the influence of smoking. Gut 1988;29:990-6.

3. Yang H, McElree C, Roth MP, Shanahan F, Targan SR, Rotter JI. Familial empirical risks for inflammatory bowel disease: Differences between Jews and non-Jews. Gut 1993;34:517-24.

4. Steinlauf AF, Present DH. Medical management of the pregnant patient with inflammatory bowel disease. Gastroenterol Clin North Am 2004:33:361-85.

5. Gorgun E, Remzi FH, Goldberg JM, et al. Fertility is reduced after restorative proctocolectomy with ileal pouch anastomosis: A study of 300 patients. Surgery 2004;136:795-803.

6. Khosla R, Willoughby CP, Jewell DP. Crohn's disease and pregnancy. Gut 1984;25:52-6.

7. Subhani JM, Hamilton MI. Review article: The management of inflammatory bowel disease during pregnancy. Aliment Pharmacol Ther 1998;12:1039-53.

8. Bush MC, Patel S, Lapinski RH, Stone JL. Perinatal outcomes in inflammatory bowel disease. J Matern Fetal Neonatal Med 2004; $15: 237-41$.

9. Mottet C, Juillerat P, Gonvers J, et al. Pregnancy and Crohn's disease. Digestion 2005;71:54-61.

10. Dejaco C, Angelberger S, Waldhoer T, et al. Risk factors for pregnancy outcome in patients with inflammatory bowel disease (IBD). Gastroenterology 2006;130 Suppl 2:A-39(Abst).

11. Carter MJ, Lobo AJ, Travis SPL; IBD Section, British Society of Gastroenterology. Guidelines for the management of inflammatory bowel disease in adults. Gut 2004;53(Suppl V):V1-16.

12. Mahadevan U, Sandborn WJ, Li DK, Hakimian S, Kane S, Corley DA. Pregnancy outcomes in women with inflammatory bowel disease: A large community-based study from Northern California. Gastroenterology. 2007;133:1106-12

13. Cornish J, Tan E, Teare J, et al. A meta-analysis on the influence of inflammatory bowel disease on pregnancy. Gut 2007;56:830-7.

14. Cappell MS, Colon V, Sidhom OA. A study of eight medical centers of the safety and clinical efficacy of esophagogastroduodenoscopy in 83 pregnant females with follow-up of fetal outcome with comparison control groups. Am J Gastroenterol 1996; 91:348-54.

15. Qureshi WA, Rajan E, Adler DG, et al. ASGE Guideline: Guidelines for endoscopy in pregnant and lactating women. Gastrointest Endosc 2005;61:357-62.

16. Neissner M, Volk BA. Altered Th1/Th2 cytokine profiles in the intestinal mucosa of patients with inflammatory bowel disease as assessed by quantitative reversed transcribed polymerase chain reaction (RT-PCR). Clin Exp Immunol 1995;101:428-35.

17. Alstead EM, Ritchie JK, Lennard-Jones JE, Farthing MJ, Clark ML. Safety of azathioprine in pregnancy in inflammatory bowel disease. Gastroenterology 1990;99:443-6.

18. Francella A, Dyan A, Bodian C, Rubin P, Chapman M, Present DH. The safety of 6-mercaptopurine for childbearing patients with inflammatory bowel disease: a retrospective cohort study. Gastroenterology 2003;124:9-17.

19. Present DH, Meltzer SJ, Krumholz MP, Wolke A, Korelitz BI. 6-mercaptopurine in the management of inflammatory bowel disease: Short- and long-term toxicity. Ann Intern Med 1989;111:641-9.

20. Chow M, Koo J, Ng P, Rubin H. Random population-wide genetic damage induced in replicating cells treated with methotrexate. Mutat Res 1998;413:251-64.
21. Kremer JM. Toward a better understanding of methotrexate. Arthritis Rheum 2004;50:1370-82.

22. Temprano KK, Bandlamudi R, Moore TL. Antirheumatic drugs in pregnancy and lactation. Semin Arthritis Rheum 2005;35:112-21.

23. Moskovitz DN, Bodian C, Chapman ML, et al. The effect on the fetus of medications used to treat pregnant inflammatory boweldisease patients. Am J Gastroenterol 2004;656-61.

24. Dubinsky MC. Azathioprine, 6-mercaptopurine in inflammatory bowel disease: Pharmacology, efficacy, and safety. Clin Gastroenterol Hepatol 2004:2:731-43.

25. Mahadevan U, Corley D. Aminosalicylate (ASA) use during pregnancy is not associated with increased adverse events or congenital malformations $(\mathrm{CM})$ in women with inflammatory bowel disease (IBD). Gastroenterology 2006;130(Suppl 2):A-40 (Abst).

26. Nyberg G, Haljamae U, Frisenette-Fich C, Wennergen M, Kjellmer I. Breast-feeding during treatment with cyclosporine. Transplantation 1998;65:253-5.

27. Grekas DM, Vasiliou SS, Lazarides AN. Immunosuppressive therapy and breast feeding after renal transplantation. Nephron 1984;37:68

28. Danesi R, Del Tacca M. Teratogenesis and immunosuppressive treatment. Transplant Proc 2004;36:705-7.

29. Daher S, Fonseca F, Ribiero OG, et al. Tumor necrosis factor during pregnancy and at the onset of labor and spontaneous abortion. Eur J Obstet Gynecol Reprod Biol 1999;83:77-9.

30. Vasiliauskas EA, Church JA, Silverman N, Barry M, Targan SR, Dubinsky MC. Case report: Evidence for transplacental transfer of maternally administered infliximab to the newborn. Clin Gastroenterol Hepatol 2006;4:1255-8.

31. Skomsvoll JF, Wallenius M, Koksvik HS, et al. Drug insight: Anti-tumor necrosis factor therapy for inflammatory arthropathies during reproduction, pregnancy and lactation. Nat Clin Pract Rheumatol 2007;3:156-64.

32. Roux CH, Brocq O, Breuil V, Albert C, Euller-Ziegler L. Pregnancy in rheumatology patients exposed to anti-tumour necrosis factor (TNF) therapy. Rheumatology (Oxford) 2007;46:695-8.

33. Katz JA, Antoni C, Keenan GF, Smith DE, Jacobs SJ, Lichtenstein GR. Outcome of pregnancy in women receiving infliximab for the treatment of Crohn's disease and rheumatoid arthritis. Am J Gastroenterol 2004;99:2385-92.

34. Mahadevan U, Kane S, Sandborn WJ, et al. Intentional infliximab use during pregnancy for induction or maintenance of remission in Crohn's disease. Aliment Pharmacol Ther 2005;21:733-38.

35. Stengel J, Arnold HL. Is Infliximab safe to use while breastfeeding? World J Gastroenterol 2008;14:3085-7.

36. Ostensen M, Eigenmann GO. Etanercept in breast milk. J Rheumatol 2004;31:1017-8

37. Mottet C, Juillerat P, Pittet V, et al. Pregnancy and breastfeeding in patients with Crohn's disease. Digestion 2007;76:149-60

38. Woolfson K, Cohen Z, McLeod RS. Crohn's disease and pregnancy. Dis Colon Rectum 1990;33:869-73.

39. Agret F, Cosnes J, Hassani Z, et al. Impact of pregnancy on the clinical activity of Crohn's disease. Aliment Pharmacol Ther 2005;21:509-13

40. Kane S, Lemieux N. The role of breastfeeding in postpartum disease activity in women with inflammatory bowel disease. Am J Gastroenterol 2005;100:102-5. 


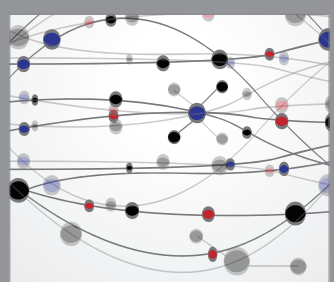

The Scientific World Journal
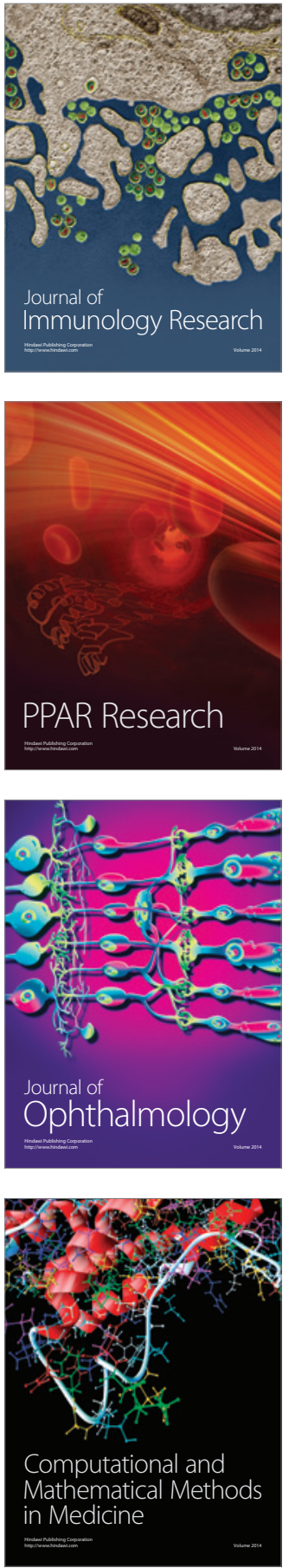

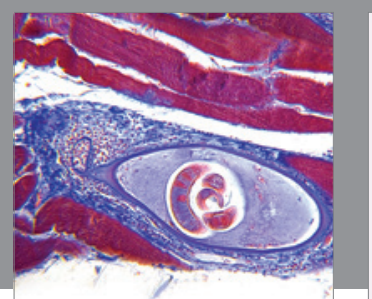

Gastroenterology Research and Practice

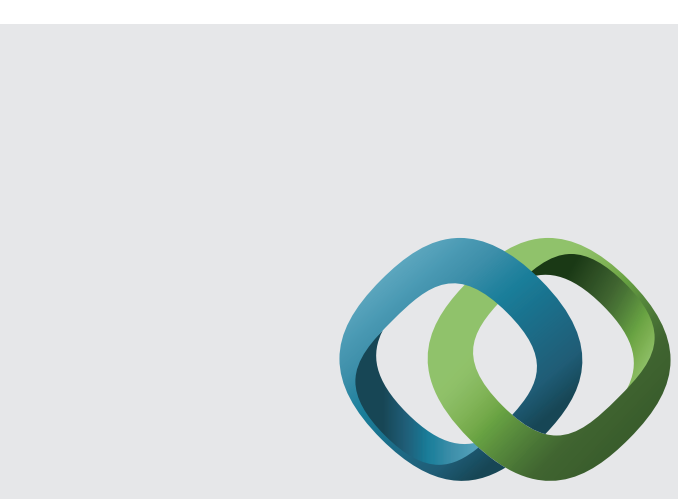

\section{Hindawi}

Submit your manuscripts at

http://www.hindawi.com
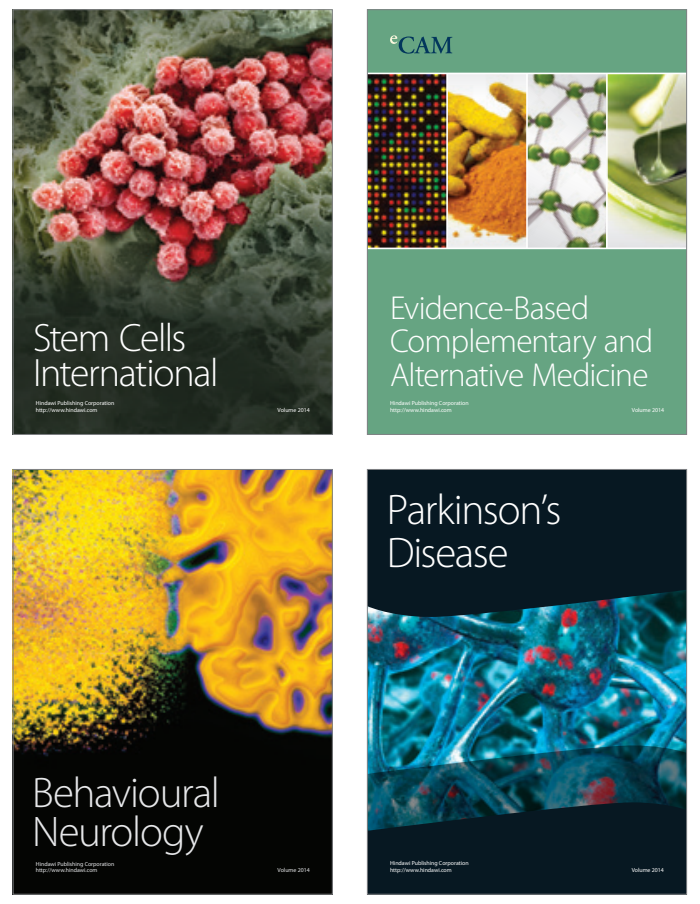
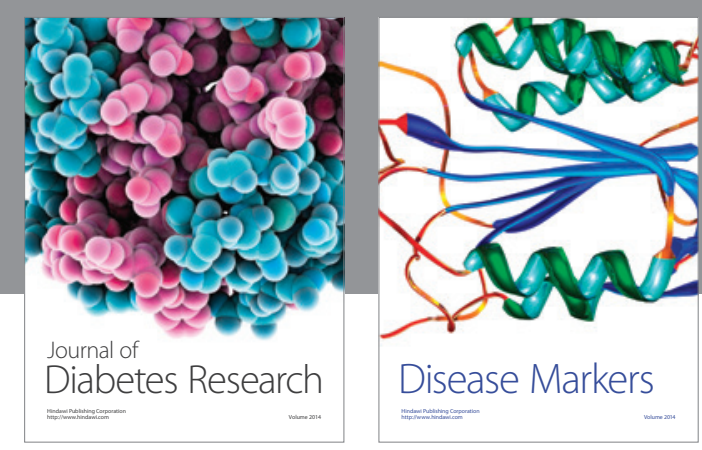

Disease Markers
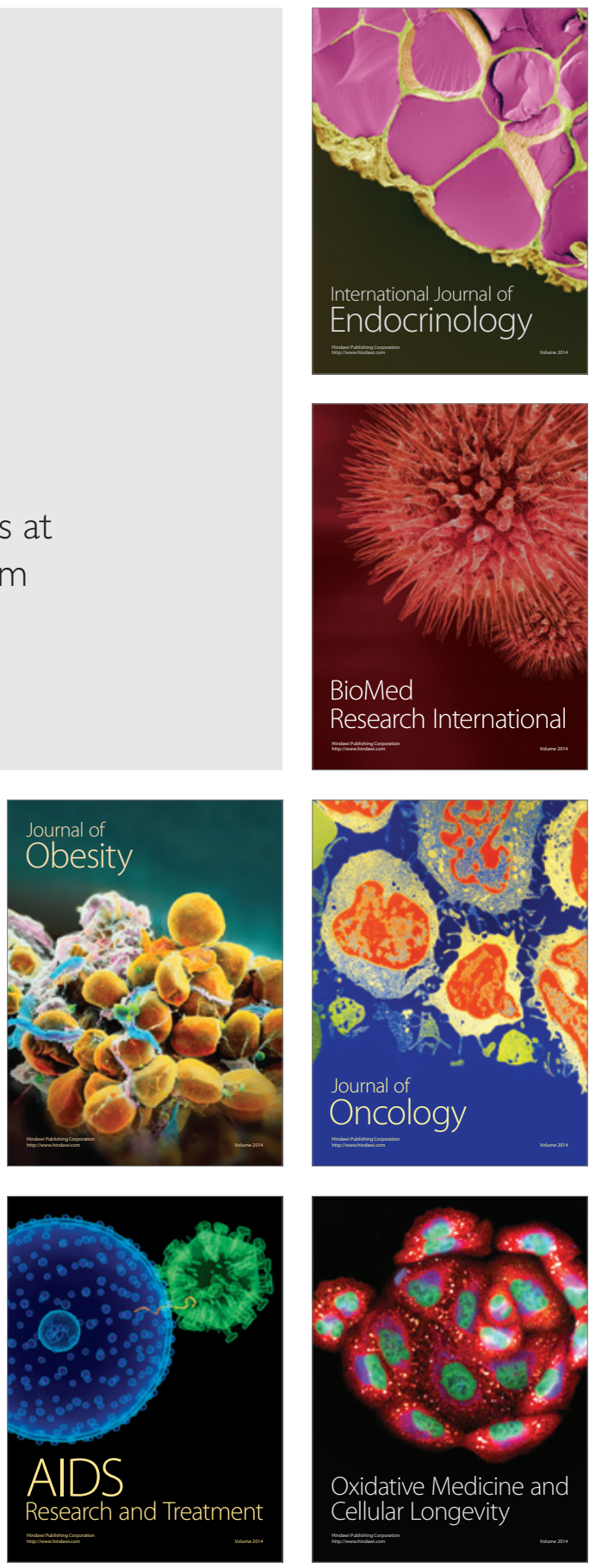